\title{
A língua ucraniana como símbolo de pertencimento e de identidade de ucraniedade em uma comunidade no sul do Brasil
}

\author{
Jakeline A. Semechechem ${ }^{a}$ \\ Neiva Maria Jung ${ }^{b}$ \\ Adriana Dalla Vecchia ${ }^{c}$
}

\begin{abstract}
Resumo
Neste artigo, temos como objetivo discutir os (des) caminhos da identidade ucraniana articulada a valores da língua ucraniana e da religião católica do rito ucraniano em uma comunidade rural multilíngue (português, brasileiro e ucraniano) de um município do Sudeste do estado do Paraná, no Sul do Brasil. Os dados discutidos são resultantes de uma etnografia da linguagem (SEMECHECHEM, 2016) e foram gerados por meio de observação participante, registro em diários de campo, entrevistas e gravações em áudio e vídeo. A perspectiva teórico-metodológica compreende multilinguismo como um conjunto de recursos comunicativos ideologicamente carregados (HEL$L E R, 2007)$ que constitui o repertório linguístico das pessoas (BLOMMAERT, 2010) e que está articulado com identidades sociais (BUCHOLTZ; HALL, 2004, 2005, 2008; OLIVEIRA, 2000). Os resultados da análise mostraram que os participantes consideram as práticas linguísticas em língua ucraniana local como simbolo de pertencimento e de identidade de ucraniedade. Essa identidade está associada à etnicidade, à religião, ao trabatho rural eà língua ucraniana e representa o que éser ucraniano de uma comunidade rural no interior do Brasil.
\end{abstract}

Palavras-chave: Lingua ucraniana. Identidade. Ucraniedade.

Recebido em 15 de janeiro de 2017 Aceito em 09 de maio de 2017

\footnotetext{
aDoutora em Letras, Estudos Linguísticos e professora da Universidade Estadual do Norte do Paraná (UENP). E-mail: jakeline.semechechem@gmail.com

bDoutora em Letras, professora da Universidade Estadual de Maringá (UEM). E-mail: neiva.jung@gmail.com 'Doutoranda em Letras na Universidade Estadual de Maringá. E-mail: adrianarevisao@gmail.com
} 


\section{Considerações iniciais}

No Brasil, temos inúmeras comunidades multilíngues constituídas pela(s) língua(s) do grupo, de imigrantes, de indígenas, das fronteiras, e pelas línguas portuguesas, geralmente a língua culta escrita ensinada nas escolas e a língua portuguesa local que se formou pelo contato com a língua do grupo. Embora tenhamos tido políticas linguísticas oficiais de proibição e de apagamento das línguas diferentes do português, contribuindo com ideologias monolíngues e de padronização da língua portuguesa, em muitas comunidades, os membros (co)produziram políticas linguísticas nas quais articularam e articulam língua, cultura e religião, por meio de valores locais atribuídos ao multilinguismo e às línguas da comunidade.

A situação de multilinguismo no município de Prudentópolis é decorrente da imigração europeia para o município no final do século XIX e início do século $\mathrm{XX}$, principalmente de populações eslavas, ucranianas e polonesas, estas em menor proporção, e alguns alemães e italianos. No dia a dia no município, mesmo após cem anos dos fluxos migratórios, é comum as pessoas se depararem com interações que envolvem o uso da língua ucraniana e da língua portuguesa, seja na cidade ou nas comunidades rurais, principalmente em algumas comunidades rurais, contrapondo-se, dessa forma, ao mito do monolinguismo no Brasil (CAVALCANTI, 2015; OLIVEIRA, 2000; ALTENHOFEN, 2013; CESAR; CAVALCANTI, 2007).

Reconhecemos políticas linguísticas como (co)produzidas no dia a dia pelas pessoas que viveram e vivem a vida na diversidade e reconhecemos, ainda, que há, conforme afirma Maher (2010), "[..] uma relação profunda, estreita, visceral entre políticas linguísticas e políticas de identidade" (p. 3637) e que "[...] a consciência de pertencer a uma minoria faz seus membros constantemente colocarem em questão suas próprias identidades" (MAHER, 2010, p. 37). Partimos de uma concepção de língua como prática social e isso significa não somente uma filiação epistemológica, a partir da qual olhamos ou interagimos com as pessoas do contexto que estudamos, mas uma postura ontológica de reconhecimento da agentividade dos nossos interlocutores. Nossa opção não é a de colocar 
${ }^{1}$ Os dados deste artigo são provenientes de pesquisa de campo, realizada em 2013, amparada nas orientações da Resolução n. ${ }^{\circ}$ 466, de 12 de dezembro de 2012 do Conselho Nacional de Saúde, aprovada pelo Comitê de Ética da Universidade Estadual de Maringá, CAAE 21583713.0.0000.0104.

2 C o n f o r m e Semechechem (2016), a língua ucraniana local é um ucraniano oral constituído pela língua ucraniana, pela língua portuguesa e pela língua polonesa, difere portanto do ucraniano culto (oral e escrito). Essas diferentes realizações do ucraniano, consequentemente, têm valores diferenciados. A língua ucraniana local além de símbolo de pertencimento, tem valor religioso, valor para as práticas sociais locais e um incipiente valor como produto cultural.

3 N o origin a 1 , "Language ideologies are productively used in the creation and representation of various social and cultural identities [...]". a realidade observada em categorias pré-definidas, mas a de estabelecer interlocução com os falantes, "dar ouvidos" (ALTENHOFEN, 2013) às formas como reconhecem os usos e valoram esses usos da língua ucraniana local em relação às suas identidades.

Assim, propomos como objetivo, para este artigo, reconhecer os (des)caminhos da identidade ucraniana articulada a valores da língua ucraniana e da religião católica do rito ucraniano em uma comunidade rural multilíngue (português, brasileiro e ucraniano) localizada a $12 \mathrm{~km}$ da cidade de Prudentópolis e colonizada predominantemente por descendentes de ucranianos, por meio de uma análise de dados gerados a partir de entrevistas semiestruturadas, anotações em diário de campo e gravações em áudio e vídeo¹. Para dar conta desse objetivo, apresentamos, na seção a seguir, uma breve discussão do que compreendemos por identidades sociais, em seguida, a partir desse posicionamento epistemológico, nossa interlocução com os dados gerados na comunidade e, por fim, algumas considerações finais.

\section{Identidades sociais em contexto de multilinguismo}

Nessa comunidade, a língua ucraniana local ${ }^{2}$ tem, dentre seus valores, o valor de pertencimento e de identidade (BUCHOLTZ; HALL, 2004, 2005, 2008; KROSKRITY, 2004) de ucraniedade. Tomamos identidade como um processo de identificação em andamento permanente, social e político, bem como um posicionamento social do eu e do outro (BUCHOLTZ; HALL, 2004), sendo sempre "um construto sócio-histórico por natureza e, por isso mesmo, um fenômeno essencialmente político, ideológico e em constante mutação" (MAHER, 1998, p. 117). Nessa perspectiva, são relevantes as ideologias linguísticas, uma vez que "são produtivamente usadas na criação e na representação de várias identidades sociais e culturais [...] $]^{3 \prime \prime}$ (KROSKRITY, 2004, p. 509) e têm papel central na construção de identidades (BUCHOLTZ; HALL, 2008).

Quando as identidades são forjadas, em relação à linguagem, tornam-se ligadas a ideologias linguísticas, que, como historicamente enraizadas e publicamente articuladas com crenças culturais sobre língua e usuários, estão entre o momento de interação e estruturas sociopolíticas mais 
${ }^{4}$ No original, "When identities are forged in relation to language, they become bound up with language ideologies, which, as historically rooted and publicity articuled statements of cultural belief about language and it users, mediate between the interactional moment and broader s o c i o p o litic a 1 structures. By the same token, ideology mediates between the interactional stances taken by speakers and the indexal relationships to identity that are there by produce". amplas. Da mesma forma, a ideologia faz a mediação entre as posições interacionais tomadas pelos falantes e as relações indexicais das identidades que são produzidas (BUCHOLTZ; HALL, 2008, p. 154) ${ }^{4}$.

Para esses autores, identidades sociais estão articuladas com ideologias linguísticas, com crenças culturais sobre línguas e seus usuários. Nesse caso, em comunidades multilíngues, os falantes geralmente percebem a sua língua em posição subalterna diante da língua oficial do país. Isso ocorre diariamente por meio da interação, em que há lutas simbólicas entre a língua do grupo e o que ela significa em termos socioculturais e afetivos para a comunidade e as ideologias do monolinguismo e da norma padrão. Segundo Milroy (2011), a padronização das línguas produziu culturas de lingua padrão, as quais orientam tanto o senso comum quanto muitas pesquisas sociolinguísticas.

Oliveira, por sua vez, discute o conceito de identidade étnica, focalizando "instâncias empíricas em que identidades globalizadoras se manifestam." Para ele, as identidades totalizantes estão em crise.

Quando, em sua movimentação no interior de sistemas sociais, os caminhos de que se valem levam-nas a viverem situações de extrema ambivalência. São seus descaminhos, ainda que não necessariamente equivocados, pois em regra tendem a ser os únicos possíveis - conjunturalmente possíveis -, na medida em que o processo de identificação pessoal ou grupal chega a estar mais condicionado pela sociedade envolvente do que pelas 'fontes' originárias dessas mesmas identidades [...]. (OLIVEIRA, 2000, p.8)

Para o antropólogo, "identidades traduzidas" seria um bom termo para exprimir a vida de homens e mulheres que são simultaneamente plurais e parciais. Trata-se de um termo que permite pensar as condições de etnização de identidades nacionais legitimadas, evidenciando a etnicidade como uma forma possível de interação entre grupos culturais no interior das sociedades envolventes dominantes, como dos brasileiros que são englobados pela população estadunidense na categoria hispânicos, submetendo a identidade a um processo de etnização, uma vez que hispânico não é nacionalidade, mas etnia. São, segundo Oliveira (2000, p.8), "condições de possibilidade de etnização das identidades nacionais de imigrantes 
5 A vind a dos imigrantes ucranianos para Prudentópolis aconteceu em três momentos. A primeira grande leva veio entre os anos de 1895 e 1896 , quando chegaram ao Paraná, principalmente imigrantes da região da Galícia e da Bukovina motivados pela campanha de recebimento de terras. A segunda leva ocorreu em 1908, com o objetivo de trazer mão de obra para a construção de estradas. E a terceira ocorreu entre a Primeira e o fim da Segunda Guerra Mundial (19141945).

${ }^{6} \mathrm{O}$ brasileiro ou língua brasileira é a denominação usada por grupos no Brasil, como por descendentes de alemães vivendo no oeste do Paraná (JUNG, 2009), para o português brasileiro falado por eles.

7 Todos os nomes são pseudônimos, escolhidos para preservar a identidade dos interlocutores da pesquisa. residentes em sociedades anfitriãs", que vivem ambivalências e conflitos resultantes de sua situação de minoria étnica, de nacionalidades inseridas no espaço de um Estado-Nação e dos contatos interculturais locais.

Neste artigo, embora talvez não estejamos reconhecendo identidades globalizadoras, estamos propondo uma interlocução com um grupo que está há mais de cem anos no Brasil e que sustenta uma identidade de ucraniedade local.

\section{O valor simbólico da língua ucraniana: pertencimento e identidade de ucraniedade}

Os imigrantes ucranianos, ao chegarem em Prudentópolis, especialmente os da uma primeira leva ${ }^{5}$, que foi grande, foram alocados em comunidades rurais. As companhias de imigração brasileiras não conseguiram atender ao pedido do governo do Estado de não designar mais do que $40 \%$ de famílias da mesma nacionalidade para viver em um mesmo local (GUÉRIOS, 2007). Este fato levou à concentração desses imigrantes em localidades rurais, o que favoreceu a língua ucraniana, que passou a ser a língua mais usada na região de Prudentópolis. Em algumas dessas comunidades, a língua polonesa também foi bastante usada (OGLIARI, 1999). Já a língua portuguesa, localmente referida como "brasileiro"6 (JUNG, 2009), era mais usada na vila comercial. Essa vila comercial mais tarde se tornou a sede urbana do município de Prudentópolis.

Os dados que mostramos e discutimos na sequência são de pessoas de uma comunidade rural e dados de falaem-interação em sala de aula de uma escola localizada nessa comunidade. Prevalece localmente um reconhecimento de que a maioria ainda fala ucraniano, inclusive pessoas que têm outra ascendência e que aprenderam a língua do grupo majoritário local, como é o caso da aluna Paula, da mãe do professor Rubens, da mãe da atendente da biblioteca, Marta, e da mãe da secretária, Eva, que se reconhecem como polonesas, mas aprenderam a língua ucraniana local ${ }^{7}$.

Emília, aluna da escola, destaca, por exemplo, em uma fala sua, que usa bastante a língua ucraniana na escola, pois a maioria, segundo ela, é ucraniana, “Também. Na escola bastante. A maioria é ucraniano né:." (linha 07). Assim como Emília, a secretária da escola, Eva, embora identifique a mãe 
polonesa como falante de ucraniano, apresenta uma visão que associa a língua ucraniana a uma identidade ucraniana.

Eva em conversa comigo [SEMECHECHEM, 2016] relatou que morava com sua mãe, próximo à Linha Verde, que seu pai já falecido era ucraniano e sua mãe, polonesa. Quando perguntei se ela falava ucraniano, ela disse que muito pouco, quem falava era a sua mãe. Em seguida, ela complementou, dizendo: 'ela é polonesa, mas fala ucraniano' (risos) (DIÁRIO DE CAMPO, 29/10/2013).

Eva usa a conjunção adversativa "mas" indicando oposição, ou seja, ainda que sua mãe seja polonesa, ela fala ucraniano. Essa marcação de oposição indexicaliza uma ideologia linguística de que quem fala ucraniano são os ucranianos, os identificados como poloneses estão invertendo a lógica dessa ideologia étnica, constituindo o que Oliveira (2000) definiu como os (des)caminhos da identidade étnica e nacional. Ser ucraniano e falar ucraniano é o pressuposto, mas ser polonês e falar ucraniano necessita de uma justificativa, por isso compreende-se por que é aceitável que, embora a mãe de Eva seja polonesa, ela fale ucraniano.

A aluna Paula, por sua vez, não se reconhece como ucraniana, mas sim polonesa, como informou em entrevista (Entrevista concedida em 02/10/2013). Era identificada pelos colegas da turma, pelos professores e pela pesquisadora, até a data da entrevista, como ucraniana.

\section{Excerto de entrevista com Paula (02/10/2013)}

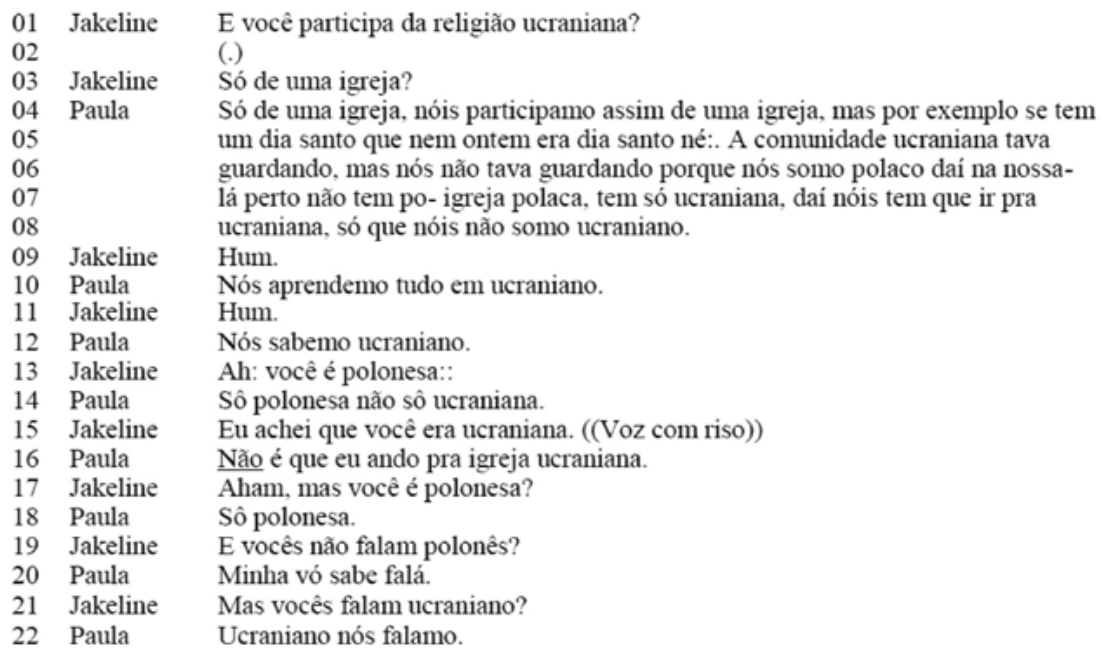


Paula se identifica como polonesa e não como ucraniana (linha 08), salientando que ela e seus familiares aprenderam tudo em ucraniano (linha 10) e que são falantes de ucraniano (linhas 12 e 22). Paula realizava práticas associadas ao grupo ucraniano, como falar ucraniano e participar da igreja católica do rito ucraniano. Na sua sala de aula, em nenhum momento, Paula foi identificada como polonesa, apenas Mariana não era reconhecida como ucraniana pelos colegas. Paula, com ascendência étnica polonesa, negociava traços reconhecidos localmente como de ucraniedade, sendo falante de ucraniano e participante da igreja católica ucraniana. A pesquisadora, também movida pelas mesmas ideologias dos participantes do que é ser ucraniano, devido a esses traços, identificou-a como ucraniana até o dia em que ela revelou, na entrevista, reconhecer-se como de origem polonesa.

Nesse caso, poderíamos tratar como um "deslocamento étnico" (OLIVEIRA, 2000), já que há uma identificação dos poloneses com a língua ucraniana. Essa identificação pode ocorrer em função de haver benefícios para essas pessoas, ou seja, ao usarem a língua ucraniana passam a fazer parte/ ser membros daquele grupo, uma questão de pertencimento. Desse modo, não se trata de um "deslocamento", mas essas interlocutoras são brasileiras para o Estado-Nação, e localmente são reconhecidas como polonesas ou ucranianas e como falantes de ucraniano.

As vozes de Emília, de Eva e de Paula representam uma voz coletiva (CARNEIRO, 2014) que associa a língua ucraniana a uma identidade ucraniana. No entanto, deve-se salientar que, mesmo a língua ucraniana sendo importante para a identidade ucraniana ou identidade cultural de ucraniedade ${ }^{8}$, a língua não está associada somente à etnia, pois a etnicidade não é o único elemento na constituição da ucraniedade local. Para ser reconhecido como ucraniano, nesse cenário multilíngue, precisa, além de falar a língua ucraniana local, fazer parte de uma religião, a católica do rito ucraniano, a qual também é associada à identidade de ucraniedade. Nesse caso, língua

${ }^{8} \mathrm{O}$ termo ucraniedade não foi cunhado neste estudo. Ele já tem sido usado por Guérios (2007), Ogliari (2008) e Gonçalves e Beló (2010). e religião, para os interlocutores da pesquisa, estão interrelacionadas. A língua portuguesa é associada à religião católica do rito latino e a língua ucraniana à religião católica do rito ucraniano, conforme reconhece Selma em sua fala. 


\section{Excerto de entrevista com Selma (30/09/2013)}

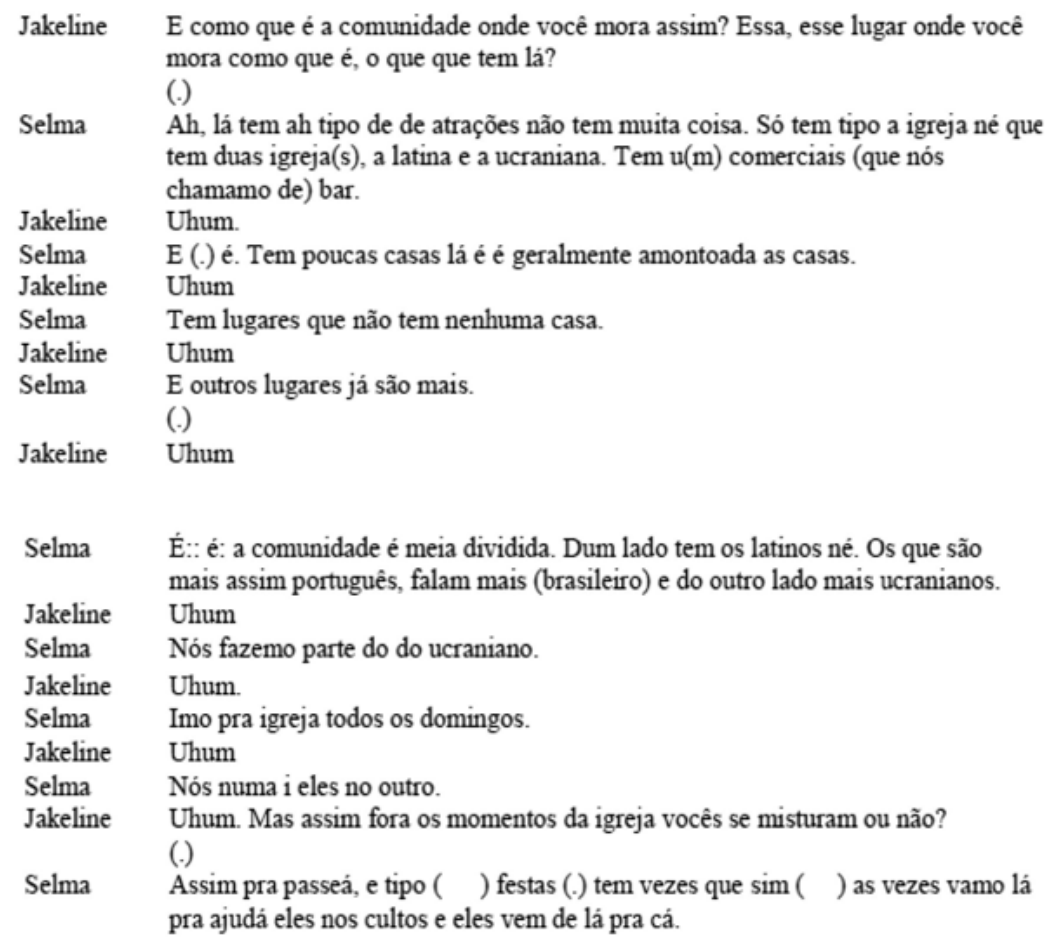

Segundo Selma, "tem duas igreja(s), a latina e a ucraniana." (linha 04), e há uma divisão na comunidade, "É:: é: a comunidade é meia dividida. Dum lado tem os latinos né. Os que são mais assim português, falam mais (brasileiro) e do outro lado mais ucranianos." (linhas 14 e 15). Esses latinos, citados por Selma, são os membros da Igreja Católica do rito latino. Selma associa a língua brasileira aos membros da Igreja Católica do rito latino e a língua ucraniana aos membros da Igreja Católica do rito ucraniano. Assim, nessa comunidade, a(s) língua(s) não está(ão) apenas associada(s) a grupos étnicos, mas a grupos religiosos. Além disso, Selma aponta para o reconhecimento de diferentes pertencimentos, brasileiros e ucranianos, sendo a língua e a religião elementos que constituem diferenças nessas categorias identitárias.

O excerto de uma aula de História no 6..$^{\circ}$, apresentado a seguir, possibilita discutir como se dá essa associação intersubjetivamente e ainda como a língua ucraniana é um 
recurso mobilizado em algumas situações no processo de autenticação de uma identidade (BUCHOLTZ; HALL, 2004, 2005).

Excerto de aula (Segmento "Fale o nome dela em ucraniano" -Aula de História - 6. ${ }^{\circ} \mathrm{G}$ ) - 28/10/2013)

01 Venâncio Dai na outra aula a gente vai ver outras coisas que eles fizeram, por exemplo, o 02 tribunal da inquisição que era punir e perseguir os que eram contra a igreja, uma coisa muito errada que a igreja fez na época né, perseguição e inquisição (.) é formar os a companhia de Jesus que é uma ordem dos padres jesuitas que existe [até hoje] né pra difundir o catolicismo por [toda] a por toda [( $\quad$ ]

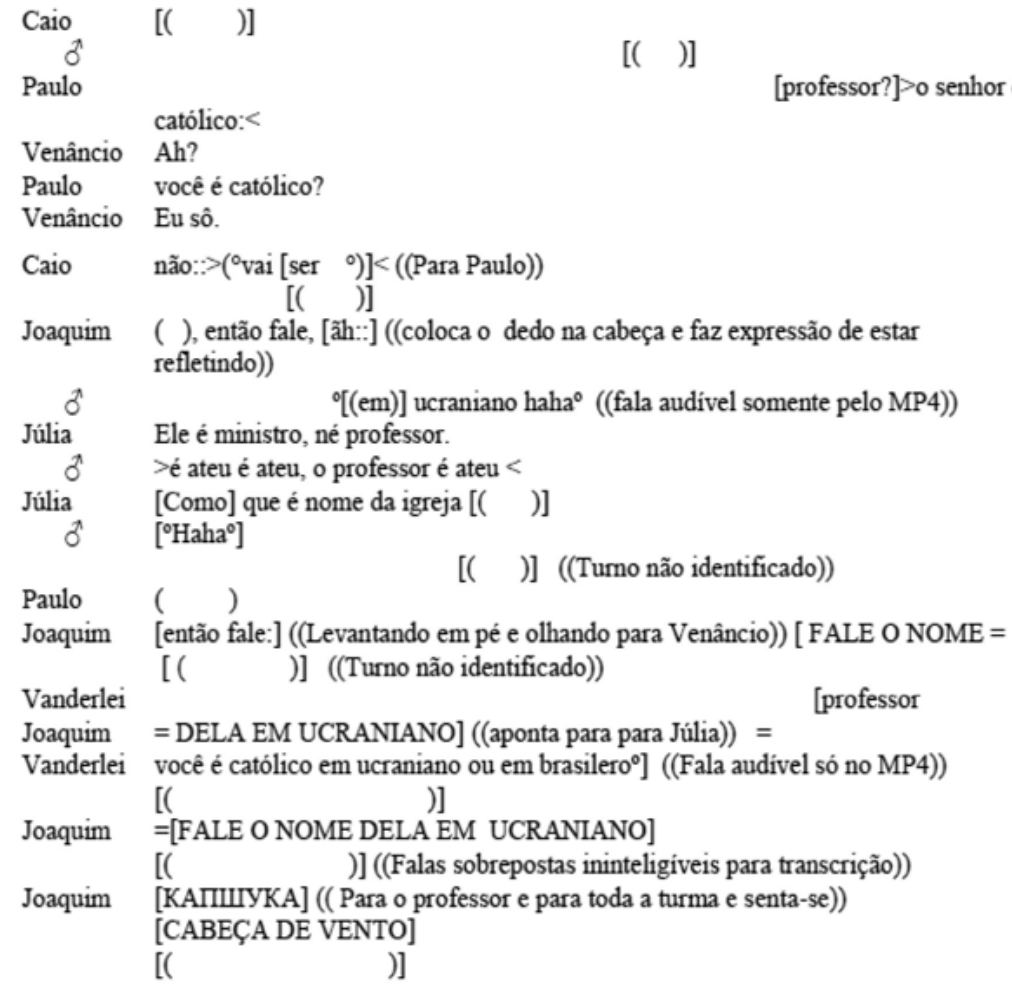

Nessa sequência da aula, Venâncio explicava para os alunos os conteúdos que iria trabalhar na aula seguinte em relação à Igreja Católica (linhas 01 à 05). Paulo se autosseleciona ainda em sobreposição ao turno de Venâncio e pergunta se ele é católico, “[professor?]>o senhor é católico:<” (linhas 08 e 09). Diante da confirmação de Venâncio, que era católico (linha 12), Joaquim fez uma solicitação para ele "( ), então fale, [ãh:::]" (linha 15) e, ao fazer uma pausa para pensar (linha 15), tem 
${ }^{9} \mathrm{De}$ acordo com Bucholtz e Hall (2005), a análise das construções identitárias compreende cinco princípios: emergência, posicionalidade, indexicalidade, relacionalidade e parcialidade. A autenticidade/ autenticação é abordada dentro do princípio de relacionalidade que identifica a identidade construída intersubjetivamente através de relações complementares, como: similaridade e diferença, autenticidade e desnaturalização e autoridade e ilegitimação.

10 No original, “[...] focuses on the ways in which identities are discursively verified $[\ldots]^{\prime \prime}$. seu turno complementado por um menino não identificado, o qual pediu para que Venâncio falasse em ucraniano " $[(\mathrm{em})]$ ucraniano haha." (linha 17). Esse complemento demonstra possivelmente a intenção que Joaquim tinha (linhas 27 e 30).

Joaquim volta a solicitar que Venâncio fale e, dessa vez, conclui o turno, dizendo em tom de voz elevado para que Venâncio falasse em ucraniano o nome de Júlia "[então fale:] ((Levantando em pé e olhando para Venâncio)) [FALE O NOME DELA EM UCRANIANO] ((aponta para Júlia))" (linhas 24 e 27). Em sobreposição ao turno de Joaquim, Vanderlei questiona se Venâncio é católico em ucraniano ou em brasileiro, "[professor você é católico em ucraniano ou em brasilero ${ }^{\circ}$ " (linhas 26 e 28). Joaquim repete em tom de voz elevado a solicitação para que Venâncio fale em ucraniano "[FALE O NOME DELA EM UCRANIANO]" (linha 30).

O fato de Venâncio assumir seu pertencimento à religião católica levou Joaquim a associá-lo à língua ucraniana, ou seja, se Venâncio é católico, então que fale em ucraniano, o que também fez o menino não identificado, que pareceu complementar a primeira solicitação de Joaquim. De forma diferenciada, reconhecendo a existência de católico em brasileiro e em ucraniano, já que, diferentemente dos outros dois meninos, questionou se Venâncio era católico em ucraniano ou em brasileiro, Vanderlei também associa a língua à religião. Percebe-se que Joaquim, o menino não identificado e Vanderlei estão movidos por uma ideologia linguística e por uma cultura local que intersecciona religião e língua ou língua e religião.

Quando Joaquim e o menino não identificado intimam Venâncio a falar em ucraniano, ocorre intersubjetivamente uma busca pela autenticidade da identidade religiosa de Venâncio e a língua ucraniana é tida como um recurso para essa autenticação. Referimo-nos à autenticidade não como uma essência inerente, mas como um processo social realizado no discurso (BUCHOLTZ; HALL, 2004). Bucholtz e Hall, em seus pressupostos sobre identidades, destacam que a autenticação é uma das táticas de intersubjetividade, um dos cinco princípios para a investigação da construção de identidades. A autenticação "[...] incide sobre as maneiras pelas quais as identidades são discursivamente verificadas" ${ }^{\prime \prime}$ (p. 601), isto é, autenticadas discursivamente, conforme o que se tem sedimentado sobre determinadas categorias sociais. 
Esses meninos, conforme seus conhecimentos do que é ser católico e do que é ser católico ucraniano, e movidos por uma ideologia linguística que intersecciona religião e língua, católico em brasileiro e católico em ucraniano, verificam a autenticidade da identidade religiosa de Venâncio. A língua ucraniana, nessa sequência interacional, é um recurso usado na autenticação da identidade religiosa e da identidade ucraniana.

Em algumas situações intersubjetivas, não dispor desse recurso, mesmo que pertencendo, de alguma forma, ao grupo étnico, pode levar a uma percepção intersubjetiva de ruptura na ucraniedade. Isso é o que Bucholtz e Hall (2005) chamam de desnaturalização, processo pelo qual uma identidade é desestabilizada, "[...] a autenticidade de uma identidade é desafiada ou questionada por causa de uma ruptura no modo como a identidade tem sido percebida" (BUCHOLTZ; HALL, 2004, p. 501) ${ }^{11}$.

No excerto do diário de campo, abaixo transcrito, apresentamos uma situação vivida por uma das autoras deste artigo (SEMECHECHEM, 2016), mas na condição de uma pessoa com ascendência ucraniana, cujo sobrenome é o mesmo de algumas pessoas da comunidade, com familiares antepassados em comum, e com possivelmente $3 .^{\circ}$ grau de parentesco. A pesquisadora experienciou sua ucraniedade colocada em xeque pela falta de domínio da língua ucraniana. Tendo em vista, no entanto, que a autenticação da identidade é sempre relacional e não fixa, a pesquisadora negociou com outro elemento constituinte da ucraniedade, a religião.

Na saída da Igreja, encontrei uma senhora idosa com quem eu conversara no posto de saúde dias antes, ela não falava tudo em português, precisou seu filho fazer traduções para o ucraniano durante nossa conversa e vice-versa. Essa senhora falou algo para uma mulher que não pude ouvir. Elas vieram até mim juntamente com Tereza e a mulher que estava ao lado da senhora, a qual me disse: 'Quer dizer que você é Semechechem também? Nossa parente'. Eu disse que sim, provavelmente tínhamos algum parentesco pelo que tinha

11 No original, "Denaturalization may also occur when the authenticity of an identity is challenged or questioned because a rupture of that identity has been perceived." conversado com a outra senhora no posto de saúde uns dias antes. Então, ela me disse: 'Mas que tipo de ucraniana é você que não fala a língua?' Justifiquei para ela por que não falo ucraniano. Na sequência ela disse: 'Mas se é católica então é uma das nossas'. Ela começou a perguntar sobre meus familiares antepassados (DIÁRIO DE CAMPO, 01/10/2013). 
Nessa situação, por não falar ucraniano, a pesquisadora foi questionada, "Mas que tipo de ucraniana é você que não fala a língua?", precisando prestar contas disso. Embora a pesquisadora não falasse ucraniano, no entanto, o fato de ela ir à igreja a fez ser reconhecida como pertencente ao grupo. A falta da língua ucraniana da pesquisadora foi compensada pela adesão à religião e a sua presença numa celebração num dia santo ${ }^{12}$, sendo essa relação com a religião elemento importante para a negociação da ucraniedade. Ou seja, ter ascendência étnica e participar das práticas religiosas podem garantir reconhecimento de pertencimento e a autenticação da ucraniedade. Conforme destaca Wang (2013), a autenticidade é algo multifacetado, dinâmico e ajustável, em vez de algo pré-determinado, monolítico, essencializado, que evolui fora das práticas sociais e dos processos complexos de negociação, ou seja, de autenticação.

A religião, assim como a etnicidade e a língua, é importante na constituição da identidade cultural de ucraniedade. Na fala da professora Edilaini, exposta no excerto a seguir, essa tríade mostra-se relevante para essa identidade e para o pertencimento ao grupo.

\section{Excerto de entrevista com Edilaini (07/10/2014)}

12 Era dia de Nossa Senhora do Patrocínio, $\mathrm{p}$ a d r o e i r a d a comunidade de Linha Verde.

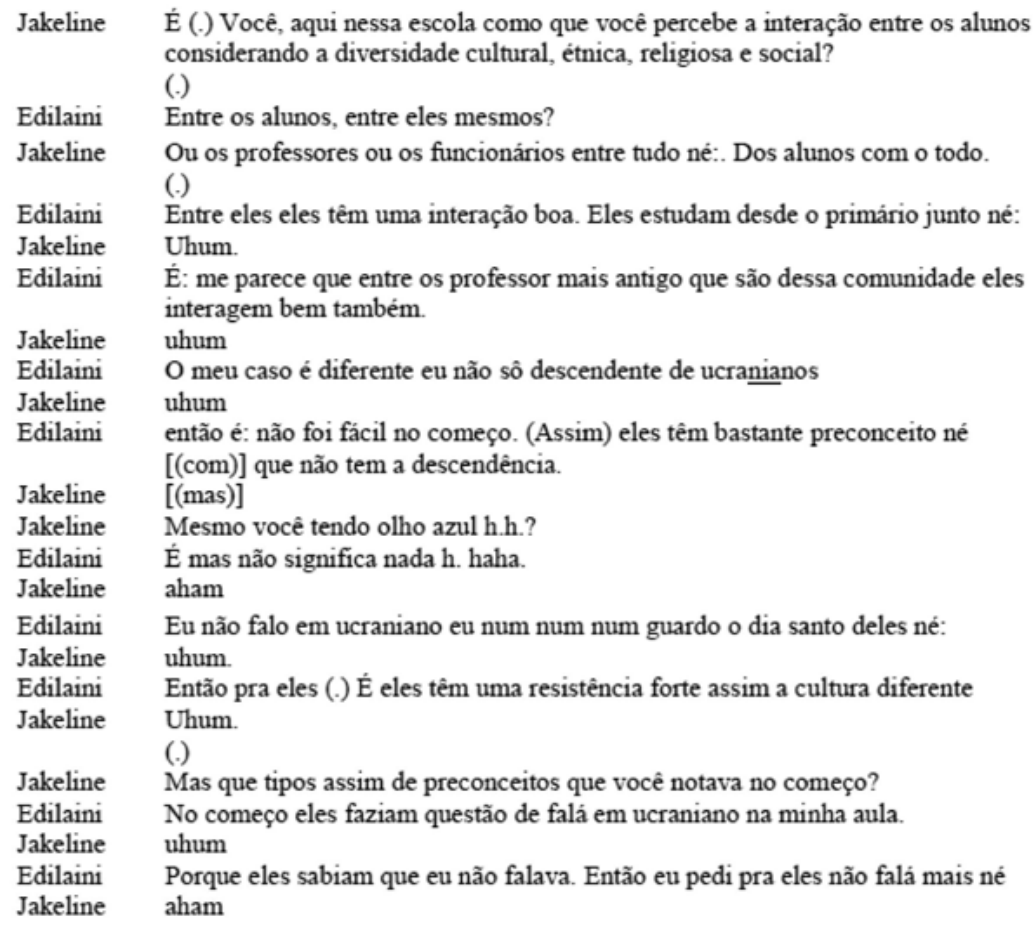

Entre eles eles têm uma interação boa. Eles estudam desde o primário junto né: Uhum.

É: me parece que entre os professor mais antigo que são dessa comunidade eles interagem bem também.

uhum

O meu caso é diferente eu não sô descendente de ucranianos uhum

então é: não foi fácil no começo. (Assim) eles têm bastante preconceito né $[(\mathrm{com})]$ que não tem a descendência.

[(mas)]

Mesmo você tendo olho azul h.h.?

É mas não significa nada $h$. haha.

aham

Eu não falo em ucraniano eu num num num guardo o dia santo deles né: uhum.

Então pra eles (.) É eles têm uma resistência forte assim a cultura diferente Uhum.

(.)

Mas que tipos assim de preconceitos que você notava no começo?

No começo eles faziam questão de falá em ucraniano na minha aula. uhum

Porque eles sabiam que eu não falava. Então eu pedi pra eles não falá mais né aham 
Edilaini destaca a sua dificuldade inicial na interação com os alunos, o que ela atribui ao fato de não ter ascendência étnica ucraniana, “O meu caso é diferente eu não sô descendente de ucranianos" (linha 12), de não falar a língua ucraniana e não ter as mesmas crenças religiosas, "Eu não falo em ucraniano eu numnumnum guardo o dia santo deles né" (linha 19). Edilaini destaca três elementos que tornavam relevante seu não pertencimento ao grupo: a etnia, a língua e a religião. Ainda, segundo ela, os alunos, no início de seu trabalho na escola, faziam questão de falar ucraniano porque ela não falava (linhas 25 e 27).

Embora outros elementos, como a etnia e a religião constituam a ucraniedade e seja possível, por meio deles, negociar essa identidade sem falar ucraniano, a língua ucraniana tem um papel importante em algumas situações na autenticação do ser ucraniano. Isso está presente, como vimos, nas situações em que, primeiro, o professor Venâncio foi intimado por alguns meninos a falar ucraniano, segundo, Semechechem necessitou, por falta do domínio da língua ucraniana, negociar sua ucraniedade, e, por último, Edilaini demonstrou acreditar que os alunos faziam questão de falar ucraniano na aula dela porque ela não falava essa língua, para marcar uma fronteira linguística e cultural.

A língua ucraniana é vista como símbolo importante para a ucraniedade e para a categorização de "+ ucraniano", diferentemente das categorias de "meio ucraniano", "ucraniano de 1,99" (SEMECHECHEM, 2010), ou "ucraniano só em algumas coisas" (KRAUSE-LEMKE, 2010). No excerto a seguir, temos a aluna Carla, descendente de ucranianos e participante da igreja ucraniana com funções de apóstola e leitora em ucraniano, que não se considera proficiente na língua ucraniana, bem como não costuma usar muito a língua ucraniana em casa. No excerto, Carla enfatiza a ucraniedade do namorado, categorizando-o como "ucraniano mesmo", um tipo de categorização que era comum, "bem ucraniano", "ucraniano tradicional" etc. 


\section{Excerto de entrevista com Carla (21/10/2013)}

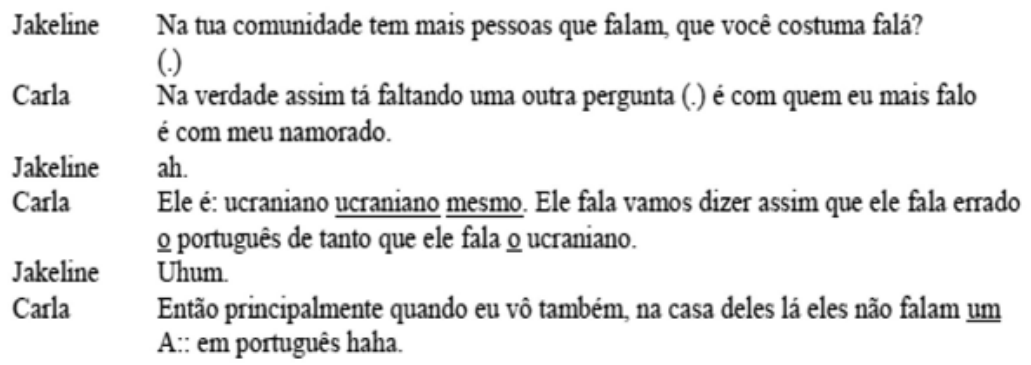

O fato de o namorado de Carla ter dificuldade na língua portuguesa, segundo ela, é de tanto ele falar em ucraniano, "Ele fala vamos dizer assim que ele fala errado o português de tanto que ele fala o ucraniano." (linhas 06 e 07), e de, na família dele, as pessoas não falarem português, quando estão em casa, "Então principalmente quando eu vô também, na casa deles lá eles não falam um A:: em português haha." (linhas 09 e 10). Para Carla, ele não é apenas ucraniano, mas "ucraniano mesmo" (linha 06). Ou seja, a língua é um importante recurso que, somado a outros símbolos, leva ao reconhecimento de mais ucraniedade. É importante ressaltar que o namorado de Carla não é apenas um falante de ucraniano, ele também é membro da igreja católica do rito ucraniano e trabalhador rural.

A fala de Rosa, secretária da escola, também apresenta uma visão do papel da língua ucraniana para a ucraniedade e para a ênfase dessa ucraniedade.

\section{Excerto de entrevista com Rosa (30/10/2013)}

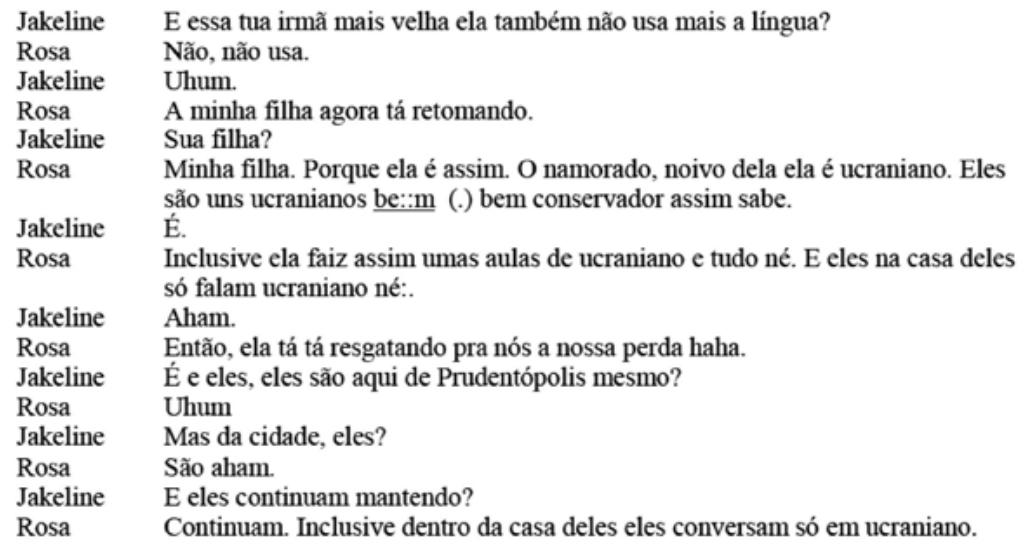


Rosa afirma que não usa a língua ucraniana e destaca que sua filha estava retomando o uso do ucraniano por causa do noivo dela que é "ucraniano"13 (linhas 04, 06 e 07). Rosa, ao fazer esse relato, salienta que o noivo e a respectiva família são ucranianos, "O namorado, noivo dela ela é ucraniano. Eles são uns ucranianos be::m (.) bem conservador assim sabe." (06 e 07). O uso do "be::m" (linha 07), seguido de pausa, mostra que Rosa pretendia intensificar a ucraniedade do noivo e de sua família. Essa pausa de Rosa, seguida de advérbio de intensidade, pode indicar o tempo que ela usou para pensar no adjetivo que usaria na sequência "bem conservador" (linha 07). Segundo ela, a família do namorado da filha falam apenas ucraniano em casa (linhas 06, 07 e 18), um índice de ucraniedade. Embora Rosa não mencione na entrevista, é de conhecimento da comunidade que a família mencionada participa da Igreja católica do rito ucraniano, ou seja, é uma família que não dispõe apenas da etnicidade e da língua, mas também da religião na constituição desse "ser" ucraniano. Eles são conversadores, conforme a fala de Rosa, por talvez residirem na cidade, um contexto que é mais heterogêneo do que as comunidades rurais, e manterem a língua ucraniana. A análise desses dados nos permite afirmar que a língua ucraniana e a participação na igreja do rito ucraniano são os dois elementos mais importantes na constituição de categorias de ucraniedade, ucraniano mesmo e ucraniano bem conservador.

A língua ucraniana é assim percebida como símbolo de identidade e de pertença (HELLER, 2003), embora não seja o único símbolo para a identidade de ucraniedade. Há uma ideologia linguística que não relaciona apenas língua e etnia, mas língua e religião, o que contribui para a construção de uma identidade étnico-linguística e religiosa, uma identidade de ucraniedade local. Há, nesse sentido, a construção local da ucraniedade, isto é, ser ucraniano na comunidade não é ter antepassados vindos da Ucrânia, mas falar ucraniano, ter o estereótipo físico, participar das práticas religiosas da igreja ucraniana.

Além de símbolo de pertencimento, o que pode ser

${ }^{13}$ Ressaltamos que é um ucraniano de Prudentópolis e não da Ucrânia. 
língua ucraniana culta. Para um grupo menor de pessoas do município, formado de religiosos e pessoas que estudaram a língua ucraniana, o ucraniano culto ou a escrita em língua ucraniana é também um capital cultural associado ao letramento acadêmico. É reconhecida como um recurso que possibilita participação em práticas letradas para além do domínio religioso, além do município e além do país, por exemplo, contatos com ucranianos e estudos na Ucrânia.

\section{Considerações finais}

Por meio da interlocução que propomos neste artigo, apresentamos que, para as pessoas dessa comunidade no interior do Brasil, a língua ucraniana, dentre seus valores, tem valor simbólico para o pertencimento (HELLER, 2003) e para a identificação com uma identidade de ucraniedade. Ser "ucraniano" nesse grupo é participar das práticas religiosas da igreja católica do rito ucraniano e dispor da língua ucraniana no repertório linguístico e fazer uso dela. Essa identidade é constituída por uma ideologia que intersecciona língua e religião e associa a língua ucraniana a um grupo étnico-linguístico e religioso. Embora reconheçamos que é possível nesse grupo ser identificado como "ucraniano" falando português, ou o português ucraniano, a língua ucraniana é em algumas situações símbolo de autenticidade, de ucraniedade, por meio de processos de autenticação (BUCHOLTZ; HALL, 2004).

Esses caminhos de que se valeram os levaram a viver situações de ambivalência, os descaminhos, e essa intersecção entre etnicidade, língua ucraniana e as práticas religiosas do rito ucraniano mantiveram coesa de alguma forma essa comunidade, possivelmente contribuindo para resistência a políticas linguísticas nacionais de proibição dessa língua e à política de valorização do português pelo Estado.

\section{REFERÊNCIAS}

ALTENHOFEN, C. V. Bases para uma política linguística das línguas minoritárias no Brasil. In: NICOLAIDES, C. et al. (Orgs). Política e Políticas Linguísticas. Campinas, SP: Pontes Editores, 2013. p. 93-116. 
BLOMMAERT, J. The Sociolinguistics of Globalization. Cambridge: Cambridge University Press, 2010.

BUCHOLTZ, M.; HALL, K. Theorizing identity in language and sexuality research. Language in Society. v.33, n.4, p. 469-515, 2004.

Identity and Interaction: A Sociocultural Linguistic Approach. Discourse Studies, London/Thousand Oaks, v.7, n. 4-5, p.585-614, 2005.

. Finding Identity: Theory and Data. Multilingua: Journal of Cross-Cultural and Interlanguage Communication, v 27 n.1-2, p. 151-163, Apr. 2008.

CARNEIRO, A. S. R. Políticas linguísticas e identidades sociais em trânsito: lingua(gem) e construção da diferença em Timor-Leste. 2014. Tese (Doutorado em Letras). Universidade Estadual de Campinas/IEL, Campinas, 2014.

CAVALCANTI, M. C. Línguas ilegítimas em uma visão ampliada de educação linguística. In: ZILLES, A. M. S.; FARACO, C. A. Pedagogia da variação linguística: língua, diversidade e ensino. São Paulo: Parábola Editorial, 2015, p. 287-302.

CESAR, A. L.; CAVALCANTI, M. C. Do singular para o multifacetado: o conceito de língua como caleidoscópio. In: CAVALCANTI, M. C.; BORTONI-RICARDO, S. M. (Orgs.) Transculturalidade, linguagem e educação. Campinas: Mercado de Letras, 2007, p. 45-66.

GONÇALVES, R., BELÓ, M. A ucraniedade na poética de Tarás Chevtchenko e Helena Kolody. Voos Revista Polidisciplinar Eletrônica da Faculdade Guairacá. Guarapuava, v.2, n.1, p. 52-71, 2010. Disponível em: < http://www.revistavoos.com.br/seer/ index.php/voos/article/view/81/4 >. Acesso em: 27 mai. 2015. GUÉRIOS, P. R. Memória, identidade e religião entre imigrantes rutenos e seus descendentes no Paraná. 2007. 292 f. Tese (Doutorado em Antropologia Social). Museu Nacional, Universidade Federal do Rio de Janeiro, Rio de janeiro, 2007.

HELLER, M. Globalization, the new economy, and the commodification of language and identity. Journal of Sociolinguistics. v. 7, n. 4, p. 473-492, Nov. 2003.

. Bilingualism as ideology and practice. In: HELLER, M. (Eds.) Bilingualism: a social approach. Basingstoke, UK: Palgrave Macmillan. 2007, p. 1-24. 
JUNG, N. M. A (re)produção de identidades sociais na comunidade e na escola. Ponta Grossa/PR: Editora UEPG, 2009.

KRAUSE-LEMKE, C. Politicas e práticas linguísticas: um estudo sobre o ensino de lingua espanhola em um contexto multilingue no Paraná, Brasil. 2010. 236 f. Tese (Doutorado em Educação). Universidade de São Paulo, São Paulo, 2010.

KROSKRITY, P. Language ideologies. In: DURANTI, A (Ed.). A Companion to Linguistic Anthropology. Malden, MA: Blackwell, 2004. p. 496-517.

MAHER, T. J. M. Sendo índio em português. In: SIGNORINI, I. (Org.) Lingua(gem) e identidade: elementos para uma discussão no campo aplicado. Campinas: Mercado de Letras, 1998. p. 115-137.

. Políticas linguísticas e políticas de identidade: currículo e representações de professores indígenas na Amazônia ocidental brasileira. Currículo sem Fronteiras, v. 10, n. 1, p. 33-48, jan./jun. 2010. Disponível em: < http://www. curriculosemfronteiras.org/vol10isslarticles/maher.pdf $>$. Acesso em: 14 jan. 2017.

MARTIN-JONES, M. Enterprising women: multilingual literacies in the construction of new identities. In: MARTINJONES, M.; JONES, K. (Eds.). Multilingual literacies: reading and writing different worlds. Amsterdam: John Benjamins, 2000. MILROY, J. Ideologias linguísticas e as consequências da padronização. In: LAGARES, X.; BAGNO, M. (Orgs.) Políticas da norma e conflitos linguísticos. São Paulo: Parábola Editorial, 2011. p. 49-88.

OGLIARI, M. M. As condições de resistência e vitalidade de uma língua minoritária no contexto sociolinguístico brasileiro. Tese (Doutorado em Letras). Universidade Federal de Santa Catarina, Florianópolis, 1999.

OLIVEIRA, R. C. Os (Des)caminhos da identidade. Revista Brasileira de Ciências Sociais. v. 15, n. 42, p. 7-21, fev. 2000. DOI: http://dx.doi.org/10.1590/S0102-69092000000100001.

SEMECHECHEM, J. A. O mutlilinguismo na escola: práticas linguísticas em uma comunidade de imigração ucraniana no Paraná. 2016. 272 f. Tese (Doutorado em Letras). Programa de PósGraduação em Letras. Universidade Estadual de Maringá, Maringá, 2016. 
SEMECHECHEM, J. A. Letramento e identidades sociais em um município multilíngue no Paraná. 2010. 185 f. Dissertação (Mestrado em Letras). Programa de Pós-Graduação em Letras. Universidade Estadual de Maringá, Maringá, 2010.

\begin{abstract}
The Ukrainian language as a symbol of membership and identity of Ukraineness in a community in the south of Brazil
\end{abstract}

In this article, we aim to discuss the ways of Ukrainian identity articulated to values of the Ukrainian language and to the Catholic religion of the Ukrainian rite in a rural multilingual community in the municipality of Prudentopolis, in the southeast of the state of Parana, in the south of Brazil. The data discussed are the result of an ethnography of language (SEMECHECHEM, 2016) and was generated through participant observation, field notes, interviews and audio and video recordings. The theoretical-methodological perspective are multilingualism as a set of ideologically informed communicative resources (HELLER, 2007) which make up our linguistic repertoires (BLOMMAERT, 2010) articulated with social identities (BUCHOLTZ, HALL, 2004, 2005; OLIVEIRA, 2000). The results of the analysis showed that the participants consider the local Ukrainian language as a symbol of membership and local identity of Ukraineness. This identity is associated with ethnicity, religion, rural work and the Ukrainian language and represents what it is to be Ukrainian from a rural community of Brazil.

Keywords: Ukrainian language. Identity. Ukraineness. 